\title{
Fast breeders: all cons, no pros?
}

\author{
Alvin M. Weinberg
}

THAT nuclear energy would grind to a halt unless a breeder were developed was understood by the original workers in nuclear energy. What was not clear then, and what is still not entirely clear, is the kind of breeder that ought to be developed. In 1952, Bennett Lewis, father of the Canadian CANDU system, along with E. $O$. Lawrence, proposed the electric breeder based on an enormous proton accelerator. A variant of electric breeding, the so-called fission/fusion hybrid is now being discussed fairly seriously. 1 , along with $\mathbf{H}$. G. MacPherson, espoused breeders based on the thorium cycle, particularly those using molten salts. And a thorium breeder based on light-water reactor technology has been built by H. G. Rickover in Shippingport, Pennsylvania. But the plutonium fast breeder, pioneered by $\mathrm{W}$. H. Zinn, gained momentum and is now essentially the only show in town.

We could always give a plausible rationale for the ultimate deployment of breeders, but we could never say when breeders, of whatever kind, would be necessary. Since the fuel cycle cost of the breeder is far less sensitive to the cost of the raw uranium than is the fuel cycle cost of non-breeder pressurized water or gascooled reactors, eventually breeders would provide cheaper energy than would nonbreeders. Our argument for aggressive development and quick deployment of the breeder was therefore based on the hope that breeders might be cheaper than nonbreeders. The only way to find whether or not this was the case was to build large breeders. This remains the strongest argument for vigorous development of a full-size fast breeder. We had two other, albeit secondary, arguments favouring quick deployment of breeders: they would confer on their users a measure of energy autarky and thus would relieve pressure on non-renewable energy sources; and their deployment would put a virtual end to the mining of uranium, the only part of the fuel cycle that poses a technically difficult problem of waste disposal.

The basic economic arguments have hardly changed in the intervening 30 years, as these proceedings of the Polytechnic of the South Bank 1978 Conference on the Fast Breeder demonstrate. The main change is the emergence of non-economic
The Fast Breeder Reactor: Need? Cost? Risk? Edited by Colin Sweet. Pp.232. (Macmillan Press: London, 1980.) £20.

issues - political, social and ethical - that were barely identifiable in the early days. As the editor, Colin Sweet, says,

It is necessary to subject the official view to a critical assessment and it was the purpose of the conference ... to do that ... the issues...go far beyond what is to be found in the official literature ... There is no question of trying . . to strike 'a balanced view,' because there is no way in which such a phrase can be interpreted.

The resulting 14 papers and five appendices examine not only the old questions (will the fast breeder be economic; and will it be safe?) but also the far broader question of whether nuclear energy itself is needed. Most of the authors are opposed to nuclear energy. Their attack on the fast breeder is an attack on nuclear energy itself. When David Widdicombe argues that nuclear energy and civil liberties are incompatible or when Professor Patricia Lindop says that "the radiation hazard to the population may prove to be the factor limiting the utilization of nuclear energy" they are calling for an end to nuclear energy, not merely an end to the fast breeder.

For those seeking a balanced account of the debate over the fast breeder reactor, these proceedings will be disappointing: it is not only that the positions are far too polarized, it is that there is no real confrontation between the different points of view. Though the nuclear advocates are called to task, their opponents alwavs have the last word. I find those last words, such as Peter Odell's claim of $70 \%$ efficiency for oil burning heaters, incomplete and tendentious; tniy scarcely conceal a profound distrust of nuclear energy.

The editor of Nature, in asking me to review this book, implied that the fast breeder reactor issue in the United Kingdom is controversial and thus that the book would be best dealt with by an outsider. As an American, I am reluctant to become involved in a family squabble. Nevertheless, for what it is worth, I offer these points for consideration.

(1) The denial of nuclear energy amounts to a denial of human ingenuity.
For example, much is made of the loss of civil liberties entailed in nuclear energy. Yet, since Strategic Air Command bases can be made secure with minimal infringement on civil liberties, I don't see why the same cannot be done for nuclear sites.

(2) I have never been a strong supporter of the fast breeder reactor; I have always thought the thermal system based on thorium was a better bet. In the best of all possible worlds, many different breeders would be pursued, and the choice of the fast breeder would not have pre-empted development of the alternatives to the point where a fair comparison could be made between the various possibilities.

But in the real world, the fast breeder is now practically the only option. Despite the real possibility that fast breeders will prove too costly to make economic sense in the short run, active development of the breeder is at least as sensible as is active development of solar energy. The two are the only inexhaustible energy sources that we know to be technically feasible. We shall know the price of the breeder only by building several, just as we shall know the price of solar power towers only after we have built some.

(3) In the final analysis, we must decide whether the risk in going ahead with the fast breeder and then discovering we do not need it (fusion may work, or solar may be cheap) is less than the risk of not going ahead with the breeder and discovering in, say 2025 , that we need it. Considering what is at stake - our energy future, not to speak of the spectre of $\mathrm{CO}_{2}$ induced climate change - I believe we must go ahead with development of the breeder, expensive though this may be.

France, which has chosen to generate 40 per cent of its primary energy from nonfossil sources by 1990, has decided to depend on nuclear energy - that is, on the breeder. It is not unlikely that, in the year 2000 , the rest of us may envy the degree of energy autarky enjoyed by France as a result of this decision while we bicker over whether nuclear energy can be mended, and fight over the oil that remains in the Middle East.

Alvin M. Weinberg is Director of The Institute for Energy Analysis, Oak Ridge Associated Universities, Tennessee. 